$\mathbf{R}_{\text {ESEARCH }} \mathbf{P}_{\text {APER }} \longrightarrow$ FOOD SCIENCE

\title{
Development and quality evaluation of stevia based cake and biscuits
}

\author{
Paridhi Bijarnia, Madhu Goyal, Vimla Dunkwal and Reema Rathore
}

\begin{abstract}
The present study was undertaken to develop cake and biscuit with sugar, sucralose, stevia leaf powder and stevia liquid extract. Organoleptic evaluation of cake and biscuit based on stevia leaf powder, stevia liquid extract, sucralose and sugar was carried out using nine point hedonic rating scale. Non-significant difference in mean overall acceptability scores was observed between sucralose and stevia liquid extract based samples with maximum scores for control samples. Stevia leaf powder based samples scored minimum. Biscuit samples could be stored at room temperature till 15 days with nonsignificant variations and thereafter the scores kept declining till two months, thereby falling in the category of "liked slightly to "disliked slightly". During storage the moisture content and CFU count of the products was found to be satisfactory.
\end{abstract}

Key Words : Biscuit, Cake, Stevia, Sucralose, Organoleptic evaluation, Shelf-life

How to cite this article : Bijarnia, Paridhi, Goyal, Madhu, Dunkwal, Vimla and Rathore, Reema (2017). Development and quality evaluation of stevia based cake and biscuits. Food Sci. Res. J., 8(1): 64-69, DOI : 10.15740/HAS/FSRJ/8.1/64-69. 